\title{
Mothers’ perspectives of newborn hearing screening programme
}

\author{
Mercy E. Jatto ${ }^{1}$, Segun A. Ogunkeyede ${ }^{1,2}$, Adebolajo A. Adeyemo, ${ }^{1,3}$ Kazeem Adeagbo $^{1}$ and \\ Orinami Saiki ${ }^{1}$
}

Ghana Med J 2018; 52(3): 158-162 doi: http://dx.doi.org/10.4314/gmj.v52i3.9

\author{
${ }^{1}$ Department of Otorhinolaryngology, University College Hospital, Ibadan, Nigeria, \\ ${ }^{2}$ University College Hospital, Ibadan, Nigeria \\ ${ }^{3}$ Institute of Child Health, College of Medicine, University of Ibadan, Ibadan and University College Hospital, \\ Ibadan, Nigeria
}

Corresponding author: Dr. S. A Ogunkeyede

Conflict of interest: None declared

E-mail: segunkeyede@yahoo.com

\section{SUMMARY}

Background: Newborn hearing screening programs identifies newborns with hearing loss. The early identification enables prompt intervention through hearing rehabilitation. Accurate knowledge of the program and its benefit will impact on the uptake of the program by the citizenry. We hypothesized that there is a gap in the knowledge of parents on hearing screening and rehabilitation measures in Nigeria.

Aim: To determine the knowledge and perceptions of mothers of newborn children on hearing screening.

Methods: A cross sectional observational study among mothers of newborn children at immunization clinics. Semi structured questionnaire on gestational duration, mode of delivery, birth asphyxia, knowledge on hearing loss and newborn hearing screening were administered.

Results: Participants were 48 mothers with age range from 18 to 42 years. Awareness of newborn hearing screening was poor among the mothers; sources of information on newborn hearing screening were antenatal clinic, mass media and friends. The educational level of the participants had no association with awareness ( $p=0.11)$, but the willingness to accept newborn hearing screening, was associated with socioeconomic status $(p=0.04)$ and the level of education $(\mathrm{p}=0.02)$. The participants were not aware of factors responsible for hearing loss in childhood.

Conclusion: There is inadequate knowledge about newborn hearing screening and risk factors for infant hearing loss among the mothers, though they demonstrate willingness to accept the newborn hearing screening.

Funding: None declared

Keywords: Hearing loss, hearing screening, immunization, mother, newborn

\section{INTRODUCTION}

Universal Newborn Hearing Screening facilitates early detection of sensorineural hearing loss, a prevalent form of sensory disability during childhood. ${ }^{1,2}$ Sensorineural hearing loss occurs in $1-3$ per 1,000 live births in term healthy neonates, and $2-4$ per 100 in high-risk infants. ${ }^{3,4}$ Factors responsible for hearing loss in newborn may be biological, environmental, congenital or perinatal in nature. Other factors include prematurity, low birth weight, asphyxia, neonatal intensive care unit admission, parental consanguinity, inherited syndromes, congenital infections and postnatal infections. ${ }^{5}$ Hearing loss in infancy is often permanent and disabling, affecting speech and language development, cognitive function, intellect, cultural, emotional and socioeconomic development. ${ }^{6,7}$
Avoidance of these consequences requires identification of hearing loss in infants at the earliest opportunity ${ }^{8}$ and early commencement of rehabilitative measures. Early hearing loss detection and intervention provides better expressive speech and language outcomes, thus decreasing the burden of permanent hearing loss. ${ }^{9}$ Delay in diagnosis has great consequences on learning with limitation of educational opportunities, this is because schools are often auditory-verbal environments. ${ }^{10}$ Prompt diagnosis through newborn hearing screening and proper rehabilitative measures will therefore improve long-term outcomes. ${ }^{11}$

The period from the 25th week of gestation to the 6th month of life is most critical to the development of the neurosensory part of the auditory system. 
During this period the hair cells of the cochlea, the axons of the auditory nerve and the neurons of the temporal lobe auditory cortex are tuned to receive signals of specific frequencies and intensities. ${ }^{12,13}$

Intervention during this period of rapid brain growth is often cost effective and associated with the best outcomes. ${ }^{13,14}$ Early acoustic stimulation, especially at 6th month of life, leads to increased nerve connections and consequently better rehabilitation of auditory pathways. ${ }^{15}$ This further emphasizes the need for early identification of auditory impairment through the newborn hearing screening.

These screening tests are simple and non-invasive. Currently, two tests are particularly suitable for screening hearing in newborns: otoacoustic emission measurements and auditory brainstem response (ABR) test. ${ }^{16}$ Newborn hearing screening (NHS) is a standard of care for neonatal hearing health in developed countries, but it is not routinely done in developing countries like Nigeria. There is presently no national policy for NHS in Nigeria, and activities in NHS are limited to a few research studies. ${ }^{7}$ Parental perception, educational level, family income, and other social factors could limit the timely screening and treatment. ${ }^{17}$ Therefore, it is important to determine the perspectives of parents and caregivers towards NHS for appropriate advocacy interventions. This study explored the perspectives of mothers on NHS in Nigeria.

\section{METHODS}

This was a qualitative cross-sectional study among mothers of neonates at immunization clinics in Southwest Nigeria. Institutional ethical clearance (UI/EC/15/0113) was obtained for the study. Through non-probability purposive sampling, two routine immunization centers were selected in Ibadan North local government area, Ibadan, Nigeria based on accessibility. Consenting mothers were recruited by a convenient sample technique and they answered a semi structured questionnaire in a face-to-face interview. These included questions on gestational duration, mode of delivery, birth asphyxia, congenital infections, maternal immunization and knowledge of newborn hearing screening.

The socioeconomic status was determined by the mother's job ${ }^{18}$ : High socio-economic status was classified as class I, middle socioeconomic status as class II and III while low socio-economic status as class IV and V.

\section{Statistics}

To ensure research reliability, an initial draft of the questionnaire was subjected to a peer review and then pretested.
The pre-tested questionnaire was subjected to a reliability test using the Cronbach's Alpha model and a reliability co-efficient of 0.78 was obtained. All obtained data were analyzed using IBM-SPSS 20, Mann-Whitney test was applied and significant statistical level was set at p $<0.05$.

\section{RESULTS}

The 48 mothers interviewed in this study, delivered their children in tertiary and secondary health care units at term. Their ages ranged between 18 - 42 years (mean age was 28 years \pm 2.41 ). Majority of the mothers had tertiary education though they had low socioeconomic status (Table 1).

Table 1 Socio-demographic profile

\begin{tabular}{|l|l|l|}
\hline \multirow{2}{*}{ Item } & Response & $\begin{array}{l}\text { Total } \\
\mathbf{n}=\mathbf{4 8}\end{array}$ \\
& & \\
\hline \multirow{2}{*}{ Mothers educational status } & No formal education & $4(8.2 \%)$ \\
\cline { 2 - 3 } & Primary & $10(20.8 \%)$ \\
\cline { 2 - 3 } & Secondary & $7(14.6 \%)$ \\
\cline { 2 - 3 } & Tertiary & $27(56.2 \%)$ \\
\hline \multirow{2}{*}{ Mothers socioeconomic status } & Low & $23(47.9 \%)$ \\
\cline { 2 - 3 } & Middle & $17(35.4 \%)$ \\
\hline & High & $8(16.6 \%)$ \\
\hline & & \\
\hline
\end{tabular}

All the mothers attended antenatal clinic and had immunization against tetanus infection, though none had immunization against congenital infectious teratogens that predisposes to hearing loss such as: toxoplasmosis, rubella, CMV, herpes simplex, and syphilis. Thirty mothers (62.5\%) were not aware of NHS, while those who had awareness of NHS derived their information from antenatal clinic (27.8\%), mass media/socio-media (11.1\%), friends/family members (16.7\%), and literature/ online internet facilities (44.4\%). The awareness of NHS was significantly associated with socioeconomic factors $(p=0.02)$ and increase in parity $(p=0.04)$ but not with the educational level $(\mathrm{p}=0.11)$.

Majority of the mothers (91.7\%) expressed willingness to accept hearing assessment of their child and agreed that the NHS should be routine after child birth before hospital discharge (Table 2), while $85.4 \%$ of the mothers agreed that NHS is relevant to the health care of the child (Table 3).

The willingness to accept neonatal hearing screening increases with increase in level of education $(p=0.001)$ and socioeconomic status $(\mathrm{p}=0.05)$. 
Table 2 Perspective of mothers on newborn hearing screening at birth

$\begin{array}{lll}\begin{array}{l}\text { Do you agree that all } \\ \text { babies should have } \\ \text { hearing screening }\end{array} & \text { Response } & \text { Frequency } \\ \text { at birth? } & \text { Strongly Disagree } & 2(4.2 \%) \\ & \text { Disagree } & 2(4.2 \%) \\ & \text { Agree } & 29(60.4 \%) \\ & \text { Strongly Agree } & 15(31.3 \%) \\ & \text { Total } & \mathbf{4 8 ( 1 0 0 . 0 \% )}\end{array}$

Table 3 Perspective of mothers on the relevance of newborn hearing screening

\begin{tabular}{|l|l|l|}
\hline & Response & $\begin{array}{l}\text { Frequen- } \\
\text { cy }\end{array}$ \\
\hline $\begin{array}{l}\text { Do you think newborn } \\
\text { hearing screening is } \\
\text { relevant to your child's } \\
\text { Care? }\end{array}$ & Totally Irrelevant & $2(4.2 \%)$ \\
\cline { 2 - 3 } & Not sure & $5(10.4 \%)$ \\
\hline & Relevant & $29(60.4 \%)$ \\
\hline & Totally Relevant & $12(25.0 \%$ \\
\hline & Total & $\mathbf{4 8 ( 1 0 0 \% )}$ \\
\hline
\end{tabular}

The study participants were not aware of factors responsible for hearing loss in childhood, except the mothers that had previously nursed children with hearing loss (6.3\%). The participants exhibited practices that could predispose to hearing loss in newborn children, such as self-medication during pregnancy (22.9\%), non-hospital consultations during pregnancy (25\%) and use of herbs (29.1\%). None of the mothers were aware of rehabilitative measures for hearing loss.

\section{DISCUSSION}

All the mothers interviewed in this study delivered their children in tertiary and secondary health care units, but the newborn children had no neonatal hearing screening before hospital discharge, nor at the routine immunization clinics. This demonstrates the lack of policy implementation of NHS program in the Nigerian health system. Government authorities in many developing countries give low priority to hearing loss, despite its enormous negative socioeconomic impact on the child, the family and the community. ${ }^{19,20}$ This stance by the authorities is probably due to lack of recognition of the advantages of universal NHS. ${ }^{21}$

Other contributing factors to the lack of policy on NHS includes poor economic condition in these countries ${ }^{22}$, poor health system and insufficient funding to the health sector, high burden of HIV/AIDS and Tuberculosis ${ }^{23}$, lack of political will and internal unrest/instability in government. In addition, hearing loss is not associated with high mortality rates, thus hearing loss is viewed as less urgent ${ }^{24}$, in the primary health care/ national health care system policy framework.
However, some developing countries have hearing screening policy based on Joint Committee on Infant Hearing principles, with increase in hospital-based and community-based new born hearing screening. ${ }^{25,}$ 26, 27

According to the World Health Organization, 80\% of children with disabling hearing loss globally (7.5 million) resides in the developing countries ${ }^{28,29}$. Therefore policy makers in developing countries ought to incorporate, universal neonatal hearing screening as part of the primary health care and neonatal care. Currently the primary health care system in Nigeria does not include NHS policy, there is need therefore to advocate for its inclusion.

In this study, majority of the mothers had no information about NHS; a previous study had shown similar lack of information on the importance of NHS in the early detection of congenital hearing disorders among parents and the professionals who care for newborn children. ${ }^{30}$ The association between increased awareness and increase in the socioeconomic status and parity of the mothers underscores the relationship between health outcomes and social hierarchy. ${ }^{31}$

Though, mother's level of education is a known predictive factor of neonatal health outcome ${ }^{31}$, the educational level of the mothers in this study had no association with the awareness, and the importance of newborn screening, probably because sub-specialty medical education or health promotion is not part of regular school curriculum. This difference may also be due to the limitation of the classification system, in which the majority of the mothers were in the low socioeconomic bracket despite their educational status. The statistically significant association between increased parity and awareness of NHS may be related to the fact that increased parity gives the mothers more opportunity to visit antenatal clinics, and in the process increases contact with healthcare providers.

In this study, majority of the mothers expressed desire to have their children screened at birth, this prevalence is higher than $84.9 \%$ seen in a previous study. ${ }^{17}$ This willingness suggests that if routine newborn screening is established in Nigeria, it may likely be successful with high national coverage rate. The success rate might be further strengthened if the NHS is done before hospital discharge of the newborn child. The cultural perception that hospitals are for sick people ${ }^{33}$, it may seem incongruous to take a healthy child to health-care facilities for screening tests. 
The lack of awareness of the predisposing factors for hearing loss by the mothers, in this study is unlike the study in Karnataka, India in which the mothers exhibited good knowledge of risk factors for hearing loss. ${ }^{34}$ This difference in knowledge may be due to the existing policy and implementation of newborn hearing screening, and rehabilitation in India compared to Nigeria.

The study participants were not aware of treatment for hearing loss and that deaf children can attend school and be self-reliant. This also differs from results of a similar study in India which showed a 75\% awareness of hearing loss treatment among mothers. ${ }^{34}$ The low level of awareness could be due to lack of public awareness programs on hearing loss in Nigeria. Thus, there is a need to promote public awareness programs to improve knowledge and attitude of mothers toward infant hearing/hearing health, and implementation of policy that ensures neonatal hearing screening as part of primary health care.

The public awareness/ health promotions may also discourage the harmful cultural/health care practices, which were observed in this study. Health education at antenatal clinics and at the immunization centers will provide adequate information to mothers and caregivers on hearing screening. This action may increase demand for services and prompt utilization of health facility for newborn screening, when its available.

\section{CONCLUSION}

There is inadequate knowledge about newborn screening among mothers, with poor understanding of the risk factors for infant hearing loss. However, mothers are willing to accept the screening. There should be a national policy on NHS and increase awareness of hearing loss.

\section{REFERENCES}

1. Ruben RJ. Early identification of hearing impairment in infants and young children. NIH Consens Statement. 1993;11(1):17-29

2. Erenberg A, Lemons J, Sia C, Trunkel D, Ziring P. Newborn and infant hearing loss: detection and intervention. American Academy of Pediatrics. Task Force on Newborn and Infant Hearing, 1998-1999. Pediatrics.1999;103(2):527-530.

3. Alford RL, Arnos KS, Fox M, Lin JW, Palmer CG, Pandya A, et al. American College of Medical Genetics and Genomics Guideline for the clinical evaluation and aetiologic diagnosis of hearing loss. Genet Med. 2014; 6(4):347-755.

4. Fortnum HM. Epidemiology of permanent childhood hearing impairment: implications for neona- tal hearing screening. Audiol Med. 2003;1(3):155164.

5. Sajjad M, Khattak A.A, Bunn J.E, Mackenzie I. Causes of childhood deafness in Pukhtoonkhwa province of Pakistan and the role of consanguinity. J. Laryngol. Otol. 2008;122(10):1057-1063.

6. Sininger YS, Doyle KJ, Moore JK. The case for early identification of hearing loss in children: auditory system development, experimental auditory deprivation, and development of speech perception and hearing. Pediatr Clin North Am. 1999;46(1):1-4.

7. Olusanya BO. Hearing impairment prevention in developing countries: making things happen. Int $J$ Pediatr Otorhinolaryngol. 2000;55(3):167-171.

8. Hutt N, Rhodes C. Post-natal hearing loss in universal neonatal hearing screening communities: Current limitations and future directions. J Pediatric Child Health. 2008;44(3):87-91.

9. Friderichs N, Swanepoel D, Hall JW. Efficacy of a community-based infant hearing screening program utilizing existing clinic personnel in Western Cape, South Africa. Int J Pediatr Otorhinolaryngol. 2012;76(4):552-559.

10. Bamford J, Fortnum H, Bristow K, Smith J, Vamvakas G, Davies L, et al. Current practice, accuracy, effectiveness and cost-effectiveness of the school entry hearing screen. Health Technol Assess. 2007;11(32):1-68.

11. Meyer ME, Swanepoel D, le Roux T, van der Linde M. Early detection of infant hearing loss in the private health care sector of South Africa. Int $J$ Pediatr Otorhinolaryngol. 2012;76(5):698-703.

12. Stanley N.G, Joy V.B Auditory Development in the Fetus and Infant. Newborn Infant Nurs Rev. 2008; 8(4):187-193

13. Thompson RA, Nelson CA. Developmental science and the media: early brain development. $\mathrm{Am}$ Psychol. 2001;56(1):5-15

14. Grosse SD. Education cost savings from early detection of hearing loss: new findings. Volta Voices. 2007;14(6):38-40.

15. Joint Committee on Infant Hearing Screening. Year 2007 position statement: Principles and guidelines for early hearing detection and intervention programs. Pediatrics.2007;120(4):898-92.

16. Hayes D. Screening methods: current status. Ment Retard Dev Disabil Res Rev. 2003;9(2):65-72.

17. Yun C, Wang Z, Gao J, He P, Guo C, Chen G, et al . Prevalence and Social Risk Factors for Hearing Impairment in Chinese Children-A National Survey. Int. J. Environ. Res. Public Health 2017;14(1):88-99. 
18. Famuyiwa OO, Olorunshola DA, Derin A. Some family factors in Sickle cell anaemia in Lagos, Nigeria. Nig Med Practitioner.1998; 35: 70-73.

19. Olusanya BO. Societal impact of bilirubin-induced hearing impairment in resource-limited nations. Semin Fetal Neonatal Med. 2015;20(1):58-63.

20. Gaffney M, Eichwald J, Gaffney C, Alam S. Centers for Disease Control and Prevention. Early hearing detection and intervention among infants hearing screening and follow-up survey, United States, 2005-2006 and 2009-2010. MMWR Surveill Summ. 2014;63(2):20-26.

21. Olusanya BO. Addressing the global neglect of childhood hearing impairment in developing countries. PLoS Med. 2007;4(4):626-630

22. Olusanya BO. Hearing impairment prevention in developing countries: making things happen. Int $J$ Pediatr Otorhinolaryngol. 2000;55(3):167-17

23. Streefland P. Public health care under pressure in sub-Saharan Africa. Health Policy. 2005;71(3):375-382.

24. Olusanya BO. Can the world's infants with hearing loss wait? Int $J$ Pediatr Otorhinolaryngol. 2005;69(6):735-748.

25. Joint Committee on Infant Hearing. Year 2007 position statement: principles and guidelines for early hearing detection and intervention programs. Pediatrics. 2007; 120(4):898-911.

26. Yee-Arellano HM, Leal-Garza F, Pauli-Muller K. Universal newborn hearing screening in Mexico: Results of the first 2 years. Int J Pediatr Otorhinolaryngol. 2006;70(11):1863-1870

27. Olusanya B.O, Somefun A.O. Swanepoel de W. The need for standardization of methods for worldwide infant hearing screening: A systematic review. Laryngoscope. 2008; 118(10):1830 1836.

28. Olusanya BO, Neumann KJ, Saunders JE. The global burden of disabling hearing impairment:a call to action. Bull World Health Organ. 2014;92(5): 367-373.

29. Stevens G, Flaxman S, Brunskill E, Mascarenhas M, Mathers CD, Finucane M. Global Burden of Disease Hearing Loss Expert Group. Global and regional hearing impairment prevalence: an analysis of 42 studies in 29 countries. Eur J Public Health. 2013;23(1): 146-152.

30. Machado MS, Oliveira TMT, Cóser PL. Triagem auditiva neonatal universal: projeto piloto no Hospital Universitário de Santa Maria (RS)-Brasil. Pró-fono. 2002;14(2):199-204.

31. Lucas A.D, Gilles H.M. A Short Textbook of Preventive Medicine for the Tropics second ed.1984, pp. 270-273.

32. Yunis K, Beydoun H, Khogali M, Alameh M, Tamim H. Low socioeconomic status and neonatal outcomes in an urban population in a developing country. J Matern Fetal Neonatal Med. 2003;14(5):338-343.

33. Olusanya B.O, Okolo A. Early hearing detection at immunization clinics in developing countries. Int J Pediatr Otorhinolaryngol. 2006;70(8):14951498

34. Rohit Ravi, Krishna Yerraguntla, Dhanshree R, Gunjawate, Bellur Rajashekhar. Leslie E. Lewis. Vasudeva Guddattu. Knowledge and attitude (KA) survey regarding infant hearing loss in Karnataka, India. Int J Pediatr Otorhinolaryngol 2016;85:1-4 $\boldsymbol{\theta}$ 